Chapter 18

\title{
Antioxidant Role of Ascorbic Acid and His Protective Effects on Chronic Diseases
}

\author{
José Luis Silencio Barrita and \\ María del Socorro Santiago Sánchez \\ Additional information is available at the end of the chapter
}

http://dx.doi.org/10.5772/52181

\section{Introduction}

Ascorbic acid (AA), commonly known as vitamin C, plays an important role in the human body, although its function at the cellular level is not yet clear. It is necessary for the synthesis of collagen, a protein that has many connective functions in the body. Among the substances and structures that contain collagen are bone, cartilage and the surrounding material, as well as carrier substances and materials of union muscle, skin and other tissues. It also requires (AA) for the synthesis of hormones, neurotransmitters and in the metabolism of certain amino acids and vitamins. Participate in the liver for detoxification of toxic substances and blood level for immunity. As an antioxidant reacts with histamine and peroxide for reducing inflammatory symptoms.

Its antioxidant capacity is associated with reduced incidence of cancer. The requirement for vitamin $C$ for adults is well defined but they have not been uniform across different cultures, so their need has been defined as culture-specific. They have also defined other roles in cellular processes and reactions. Some epidemiological data mentioned its usefulness in reducing cold with increasing consumption of foods rich in vitamin, so people sometimes ingest an overdose of it. In most reports mention that discrete increases in blood levels of this vitamin reduces the risk of death in all conditions. Although there are many functions of vitamin $C$, his role in health is discussed mostly in relation to its role as an antioxidant and its effects on cancer, blood pressure, immunity, drug metabolism and urinary excretion of hydroxyproline.

Antioxidants play important roles in cellular function and have been implicated in processes associated with aging, including vascular, inflammatory damage and cancer. In the case of 
AA its antioxidant role is useful since it contributes to the maintenance of the vascular system and the reduction of atherogenesis through regulation in collagen synthesis, production of prostacyclin and nitric oxide. In addition to this antioxidant role, the AA has actions at the molecular level because it acts as a cofactor of enzymes such as dopamine hydroxylase (EC 1.14.17.1), influencing neurotransmitter concentration, improves lysosomal protein degradation and mediates consumer monosodium glutamate.

\subsection{History}

Since the nineteenth and early twentieth century research on these compounds led to the discovery of vitamins. ${ }^{4}$ Since 1901, a publication of Wildiers first described the stimulating effect of small amounts of organic material in the growth of yeast; this effect was the subject of many publications and only after several years was universally accepted. Wilders gave the name "bios" to the substance or substances causing increased growth of yeast. In the years since it was shown that bios were multiple in nature, and changes fractionated as bios I, bios IIA, IIB and others. ${ }^{5}$

1747. - Lind cured scurvy in British sailors with oranges and lemons.

1907. - It is reproduced experimental scurvy in guinea pigs.

1928. - Eascott identified bios I as meso-inositol. Szent-Gyorgy and Glen published the isolation of vitamin $\mathrm{C}$ or hexuronic acid.

1933. - Allison, Hoover and Burk describe a compound that promotes the respiration and growth of Rhizobium, which designated "Coenzyme R". Then, it is defined molecular structure and synthesis of vitamin $\mathrm{C}$.

1937. - the Nobel Prize in Chemistry was awarded to Walter Haworth for his work in determining the structure of ascorbic acid (shared with Paul Karrer for his work on vitamins) and the Nobel Prize for medicine was awarded to Albert von Szent-Györgyi Nagyrápolt for his studies on the biological functions of ascorbic acid.

\section{Definition}

Vitamin $C$ is defined as hexuronic acid, cevitáminic acid or xiloascórbic acid. The term vitamin $C$ is generally used to describe all these compounds, although the representative of which is ascorbic acid.

\subsection{Structure, formula and chemical characteristics}

Ascorbic acid is the enolic form of one $\alpha$-ketolactone. Ascorbic acid solution is easily oxidized to the diketo form referred to as dehydroascorbic acid, which can easily be converted into oxalic acid, diketogulonic acid or threonic acid. 

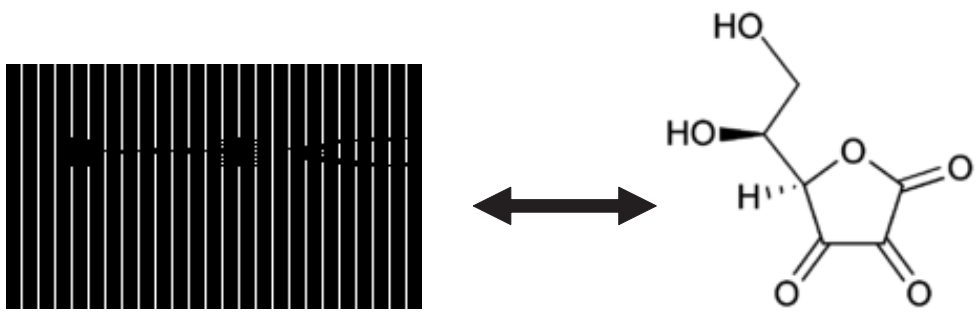

Figure 1. Structure of ascorbic acid and dehydroascorbic acid.

Name (IUPAC) systematic: (R) -3, 4-dihydroxy-5-((S) -1, 2-dihydroxyethyl) furan-2 (5H)-one; CAS Number 50-81-7: Formula: $\mathrm{C}_{6} \mathrm{H}_{8} \mathrm{O}_{6}$; mol wt. $176.13 \mathrm{~g} / \mathrm{mol}$

\subsection{Physical and chemical properties}

Ascorbic acid contains several structural elements that contribute to their chemical behavior: the structure of the lactones and two enolic hydroxyl groups and a primary and secondary alcohol group. Enediol structure motivates their antioxidant properties, as can be oxidized easily enediols to diketones. Therefore, the carbonyl groups endioles neighbors are also called reductive.

Ascorbic acid forms two bonds intermolecular hydrogen bonds (shown in red in the figure) that contribute substantially to the stability and with it the chemical qualities of the structure endiol.

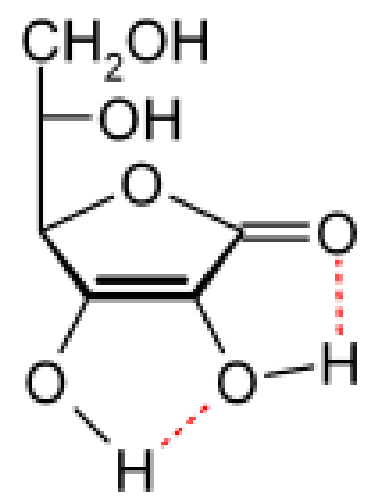

Figure 2. Hydrogen bridges formed by ascorbic acid

Ascorbic acid is rapidly interconvert in two unstable diketone tautomers by proton transfer, though it is most stable in the enol form. The proton of the enol is lost, and again acquired by the electrons from the double bond to produce a diketone. This reaction is an enol. There are two possible ways: 1, 2-diketone and 1, 3-diketone (figure 3). 

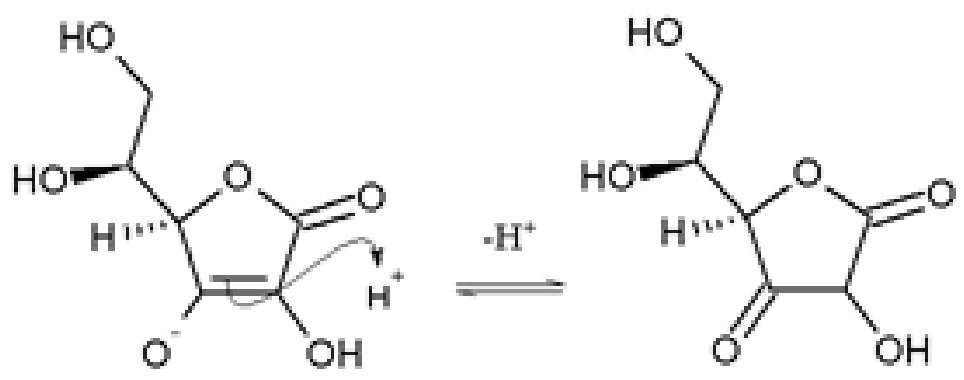

Figure 3. Nucleophilic attack on the proton ascorbic enol to give 1,3 diketone.

\subsection{Vitamers or vitameric forms}

The vitamer of a particular vitamin is any chemical compound which generally has the same molecular structure and each shows a different vitamin activity in a biological system which is deficient of the vitamin.

The vitamin activity of multiple vitamers is due to the ability (sometimes limited) of the body to convert one or many vitamers in another vitamer for the same enzymatic cofactor which is active in the body as the most important form of the vitamin. As part of the definition of the vitamin, the body can not completely synthesize an optimal amount of vitamin activity of foodstuffs simple, without a certain minimum amount of vitamer as base. Not all vitamers have the same vitamin power by mass or weight. This is due to differences in the absorption and the variable interconversion several vitamers in the vitamin.

For ascorbic acid per se, may be mentioned the following vitamers: dehydroascorbic acid, erythorbic acid (figure 4) and the following salts: sodium ascorbate, calcium ascorbate, and others. (Rogur, 2010)

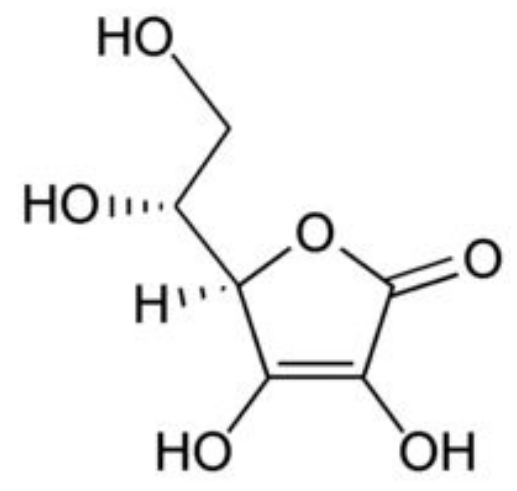

Figure 4. Structure of erythorbic acid, isoascorbic or Arabian-ascorbic 
Chemical data: IUPAC Name: D-isoascorbic acid, CAS Number: [89-65-6] Molecular formula: $\mathrm{C}_{6} \mathrm{H}_{8} \mathrm{O}_{6}$, molar mass: $176.13 \mathrm{~g} / \mathrm{mol}$; Melting point: $169-172{ }^{\circ} \mathrm{C}$

\section{Relationship with other nutrients}

\subsection{Vitamin. A and $E$}

A short-term supplementation with physiological doses of antioxidant vitamins, carotenoids and trace elements during alcohol rehabilitation clearly improves micronutrient status indicators. Heavy smokers in particular seem to respond to vitamin C supplementation (Gueguen, 2003)

In the liver accumulate micronutrients such as Vitamin A, E and iron, and therefore, in patients with hepatic impairment is a deficit of them due to reduced intake, as well as intestinal transport and liver stores. The alteration of fat soluble vitamins is especially important in patients with steatorrhea or cholestasis.

Moreover, in the alcoholic patient levels water-soluble vitamins are low due to the effect of ethanol on its metabolism, producing pyridoxine deficiency, retinol, cobalamin, folate and niacin. In fact, in chronic alcoholism may develop Wernicke encephalopathy. It has also shown a direct relationship between oxidative stress and disease severity liver, requiring the micronutrients with antioxidant activity, being increased the needs of vitamin E and C.

There are few data on vitamin needs and trace elements in burned patients. the large tissue loss, decreased gastrointestinal absorption, increased urinary losses, changes in distribution, and a high degree catabolism, that are made increased the needs of vitamins and trace elements. Clinical guidelines recommend giving also established daily requirements and additional doses of certain micronutrients.

Also, increase the intake of vitamin $\mathrm{C}(1,000 \mathrm{mg} /$ day $)$ as it promotes the healing process, and vitamin A (10,000 IU/day) for its effect immune and protective skin and mucous membranes. Also, is required additional vitamin D due to high risk of fractures in these group patients but have not yet been established Daily exact requirements.

Zinc supplement is suitable dose of $220 \mathrm{mg} /$ day, as is involved in protein synthesis and tissue regeneration. Furthermore, Chan et al indicate that in the week post-injury, there are high losses exuding of copper, being necessary to increase their requirements $(4.5 \mathrm{mg} /$ day of copper sulfate).

The increased production of oxygen species reactive in this clinical situation requires administration of antioxidants (ascorbic acid, glutathione, carotenoids, vitamin A and E) been shown to reduce mortality, protecting the micro vascular circulation, reducing the peroxidation tissue lipid. According to some authors, surgical stress may necessitate supplementation of ascorbic acid, alpha tocopherol and trace elements, associating too low preoperative levels of vitamin A $(<0.77 \mathrm{~mol} / \mathrm{L})$ with an increase of postoperative infection and mortality. At present, it is unknown whether supplementation micronutrient for a short period of time 
could restore plasma antioxidant levels after surgery. Some authors suggest that antioxidants could lead to improved metabolism and ventricular function after cardiac surgery. Also state that patient's major surgery may benefit from selenium, even before surgery, to action at the level of oxidative stress. The ESPEN recommended in these surgical patients treated with parenteral nutrition, supplement micronutrient recommended daily doses, the vitamin supplementation is unnecessary if the patient is on concomitant enteral nutrition, oral or parenteral.

\subsection{Minerals such as selenium, iron and zinc}

Recent studies have shown that in patients with inflammatory bowel disease there is a correlation between the level of some antioxidants such as selenium, vitamin $\mathrm{C}$ and $\mathrm{E}$ and clinical improvement and reduction in serum levels of TNF- $\alpha$ and decrease in steroid dose to $65 \%$. Low serum zinc levels have been correlated with increased blood pressure, disease coronary type II diabetes mellitus and hyperlipidemia. Also, high intake of magnesium (> 500-1000 mg/day) can lower high blood pressure, and be effective in acute myocardial infarction and atherosclerosis. Houston recommended to prevent the emergence and development of hypertension, administration of additional vitamins and trace elements. Finally, oxidative stress plays an important role in the initiation and maintenance of the pathogenesis of cardiovascular disease and its complications. For some authors, antioxidants such as vitamins $\mathrm{E}$ and $\mathrm{C}$, beta-carotene, selenium and zinc, may act by reducing the cardiovascular risk, although evidence is limited.

Malnutrition is a common feature of inflammatory intestinal diseases, being frequent the deficit of vitamins $B_{12}, A, D, E$ and $K$, steatorrhea, ileal resection or extensive lesions in the intestine. GI bleeding contributing to iron losses, and through diarrhea and fistulas is loss of electrolytes and trace elements (copper, magnesium, selenium and zinc).

The role of antioxidant micronutrients in the clinical and functional improvement has been described by different authors. Thus, a low intake of selenium, beta-carotene and vitamins $\mathrm{E}$ and $C$, can reduce the body's natural defenses and increase inflammation of the airways, and therefore the selenium (100-200 ug/d) been associated with improved lung function, especially in smokers. Gazdik et al indicate that supplementation of $200 \mathrm{ug} / \mathrm{d}$ of selenium in asthmatic patients produced a statistically significant decrease in the use of corticosteroids. Loannidis and McClave et al indicate that antioxidants such as selenium, vitamin A, vitamin $\mathrm{C}$ and vitamin $\mathrm{E}$ reduce pancreatic inflammation and pain, and prevent the occurrence of exacerbations. Recently in a double blind study in patients with chronic pancreatitis were given daily supplements of $600 \mathrm{ug}$ of selenium, 9,000 IU of beta-carotene, $540 \mathrm{mg}$ of vitamin C, 270 IU of vitamin E and 2,000 mg methionine, the pain was reduced significantly, as well as stress markers oxidative normalized plasma concentrations of antioxidants.

For some authors, parenteral administration of ascorbic acid can lower the morbidity and mortality of these patients in a randomized, double-blind placebo-controlled; we observed that mortality at day 28 decreased in the group of patients who received ascorbate and vitamin $\mathrm{E}$ by intravenous infusion. Some authors recommend increasing the contribution of antioxidants such as vitamin C, retinol, vitamin E, beta-carotene and selenium. Also appear to 
require thiamine, niacin, vitamin $\mathrm{A}, \mathrm{E}$ and $\mathrm{C}, \mathrm{B}$ complex, zinc $(15-20 \mathrm{mg} / \mathrm{day}$ and $10 \mathrm{mg} / \mathrm{L}$ intestinal leaks) and selenium (rise up to $120 \mathrm{ug} /$ day) in patients with sepsis.

\subsection{Polyunsaturated fatty acids}

Consumption of $0.6 \mathrm{mg}$ equivalents of alpha tocopherol/g linoleic acid is suitable for human adults. The minimum requirement of vitamin $\mathrm{E}$ related to the consumption of fatty acids with a high degree of unsaturation can be calculated with a specific formula that must take into account the peroxibility of polyunsaturated fatty acids is based on the results of animal experiments. But still no convincing evidence of how much vitamin $\mathrm{E}$ is required in relation to consumption of polyunsaturated fatty acids: EPA (20:5 n-3) and DHA (22:6n-3).

Studies so far show that the effects of supplementation with EPA and DHA lipid peroxidizacion increase even when the amounts of vitamin E present are adequate in relation to the oxidative potential of these fatty acids. On the other hand the calculation of the requirement for vitamin E using current data from recent consumption, show that a reduction in total fat intake with a concomitant increase in consumption of polyunsaturated fatty acids, including EPA and DHA results in an increased need intake of vitamin E. In fact the methods used to investigate the requirements of vitamin $\mathrm{E}$ and polyunsaturated fatty acid intake (erythrocyte hemolysis) and the techniques used to assess lipid peroxidation (malondialdehyde analysis, MDA) may be inappropriate for measuring a quantitative relationship between the two loads.

Therefore, further studies are needed to establish the requirement of vitamin $\mathrm{E}$ when intake of unsaturated fatty acids of longer chain increases. For this purpose it is necessary to use functional techniques based on the measurement of in vivo lipid peroxidation. Until then or until the available data suggest using the index of $0.6 \mathrm{mg}$ of alpha tocopherol per gram of ingested PUFA. However it is likely that higher levels are necessary for vitamin fats are rich in fatty acids containing more than two double bonds (Valk, 2000).

The diet of our ancestors was less dense in calories, being higher in fiber, rich in fruits, vegetables, lean meat and fish. As a result, the diet was significantly lower in total fat and saturated fat, but containing equal amounts of n- 6 essential fatty acids and n-3. Linoleic acid (LA) is the major n-6 fatty acid and alpha-linolenic acid (ALA) is the major n-3 fatty acid.

In the body, LA is metabolized to arachidonic acid (ARA), and ALA is metabolized to eicosapentaenoic acid (EPA) and docosahexaenoic acid (DHA). The essential fatty acid ratio n-6: n-3 is 1 to 2:1, with higher levels of long chain polyunsaturated fatty acids (PUFA), such as EPA, DHA and ARA, today's diet. Today this ratio is about 10 to 1 or 20 and 25 to 1 , indicating that Western diets are deficient in n-3 fatty acids compared with the diet that humans evolved and established patterns genetic.

The n-3 and n- 6 are not interconvertible in the human body and are important components of practically all cell membranes. The $n-6$ fatty acids and n-3 influence eicosanoid metabolism, gene expression, and intercellular communication cell to cell. The polyunsaturated fatty acid composition of cell membranes is largely dependent on food ingestion. Therefore, appropriate amounts of $n-6$ fatty acids and $n-3$ in the diet should be considered in making dietary recommendations. 
These two classes of polyunsaturated fatty acids must be distinguished because they are metabolically and functionally distinct and have opposing physiological functions, balance is important for maintaining homeostasis and normal development. Studies with nonhuman primates and human newborns indicate that DHA is essential for normal functional development of the retina and the brain, especially in premature babies. A balanced n-6/n-3 ratio in the diet is essential for normal growth and development and should lead to reduced cardiovascular disease and other chronic diseases and improve mental health. Although a recommended dietary allowance for essential fatty acids does not exist, an adequate intake (AI) has been estimated for essential fatty acids $n-6$ and $n-3$ by an international scientific working group. The final recommendations are for Western societies, reduce the consumption of n-6 fatty acids and increased intake of n-3 fatty acids. (Simopoulus, 2000)

\section{Vitamin C sources}

\subsection{Food sources in Mexico}

The main sources of ascorbic acid are presented in Table 1. The results of vitamin $C$ are shown as the mean and correspond to the official tables of composition of Mexican foods.

\begin{tabular}{ll}
\hline FOOD & CONCENTRATION $(\mathbf{m g} \mathbf{1 0 0 g}$ EP) \\
\hline poblan chili & 364 \\
\hline "trompito" chili & 320 \\
\hline yucca flower & 273 \\
\hline guava & 199 \\
\hline Marañon & 167 \\
\hline cauliflower & 127 \\
\hline red bell pepper & 160 \\
\hline guajillo chili & 100 \\
\hline garlic & 99 \\
\hline Nanche fruit & 86 \\
\hline orange & 76 \\
\hline manila mango & 76 \\
\hline serran chili & 65 \\
\hline pumpkin & 58 \\
\hline watercress & 51 \\
\hline beet & 20 \\
\hline cucumber & 13 \\
\hline EP = edible portion & \\
\hline
\end{tabular}

Table 1. Main sources of ascorbic acid in México 


\subsection{Fruits and vegetables}

Vitamin $C$ is a major constituent of fruits and vegetables, which also contain citric acid, oxalates and substances such as anthocyanins, coloring agents and carotenoids that are difficult to quantify when using colorimetric methods.

Currently there is great interest in relation to consumption of natural foods and mainly on the content of nutrients in fruits, vegetables and vitamin $C$. This interest is due in part to vitamin $C$ is probably one of the most widely used nutrients in the food and pharmaceutical industry. Used as a supplement, additive, preservative, as an antioxidant in processed foods. Table 2 shows the main foods that are good sources of vitamin C.

\begin{tabular}{|c|c|}
\hline FOOD & CONCETRATION $(\mathrm{mg} / 100 \mathrm{~g})$ \\
\hline Acerola & 1743 \\
\hline Coriander leaves dry & 567 \\
\hline red peppers, spicy, ripe, raw & 369 \\
\hline Orange juice, dehydrated & 359 \\
\hline Grape juice, dehydrated & 350 \\
\hline common Guavas, whole, raw & 242 \\
\hline Dried Tomato juice & 239 \\
\hline red pepper, spicy, immature, raw & 235 \\
\hline Lemon juice & 230 \\
\hline Orange juice, canned & 229 \\
\hline Col common, dehydrated & 211 \\
\hline Peppers, sweet, ripe, red, raw & 204 \\
\hline Currants, black, European, raw & 200 \\
\hline parsley, dry & 172 \\
\hline Orange juice & 144 \\
\hline green radish, raw & 139 \\
\hline Grape juice & 138 \\
\hline Orange peel, raw & 136 \\
\hline Pokeroot fruit & 136 \\
\hline Mustard seeds & 130 \\
\hline leaves of kale, boiled, drained & 93 \\
\hline Broccoli cooked & 90 \\
\hline Brussels sprouts cooked & 87 \\
\hline Lamb crude & 80 \\
\hline Leaves and stems of cress, raw & 79 \\
\hline Cauliflower, raw & 78 \\
\hline Brussels sprouts, cooked in water & 76 \\
\hline Cabbage, red, raw & 61 \\
\hline Strawberries Raw & 59 \\
\hline Papaya & 56 \\
\hline
\end{tabular}

Table 2. Acid content of ascorbic acid in different foods and different presentations 
In Table 3 shows the analysis of vitamin $C$ in different parts of the food such as edible portion thereof, the seed or plant center and the shell and stalks that are normally discarded.

\begin{tabular}{|c|c|c|c|c|}
\hline Food & Edible portion & Shell & Seed & Stem \\
\hline Apple & $\begin{array}{c}458.1 \pm 17.8 \\
(84.5)\end{array}$ & $\begin{array}{c}848.9 \pm 11.2 \\
(81.8)\end{array}$ & -- & -- \\
\hline chayote & $\begin{array}{c}7.2 \pm 0.9 \\
(94.2)\end{array}$ & $\begin{array}{c}19.9 \pm 0.5 \\
(94.2)\end{array}$ & $\begin{array}{c}266.6 \pm 6.7 \\
(90.5)\end{array}$ & -- \\
\hline onion & $\begin{array}{c}17.0 \pm 0.7 \\
(87.6)\end{array}$ & -- & -- & $\begin{array}{c}456.6 \pm 1.8 \\
(93.0)\end{array}$ \\
\hline lime & $\begin{array}{c}256.2 \pm 17.2 \\
(87.1)\end{array}$ & $\begin{array}{c}1916.5 \pm 186.7 \\
(69.5)\end{array}$ & -- & -- \\
\hline pomarrosa & $\begin{array}{c}531.7 \pm 36.4 \\
(83.6)\end{array}$ & $\begin{array}{c}623.0 \pm 35.1 \\
(82.5)\end{array}$ & $\begin{array}{c}1044.5 \pm 50.9 \\
(65.7)\end{array}$ & -- \\
\hline guanábana & $\begin{array}{c}140.7 \pm 3.6 \\
(80.0)\end{array}$ & $\begin{array}{c}82.1 \pm 4.9 \\
(81.8)\end{array}$ & & \\
\hline beat & $\begin{array}{c}70.8 \pm 6.8 \\
(85.3)\end{array}$ & $\begin{array}{c}115.8 \pm 1.2 \\
(85.8)\end{array}$ & & \\
\hline Potato & $\begin{array}{c}74.6 \pm 6.7 \\
(80.3)\end{array}$ & $\begin{array}{c}4.2 \pm 1.0 \\
(85.8)\end{array}$ & & \\
\hline
\end{tabular}

Table 3. Distribution of ascorbic acid $(\mathrm{mg} / 100 \mathrm{~g})$ in some fruits and vegetables produced in México

Below the edible portion the moisture (\%) is indicated in parenthesis. The data shown in Tables 3 through 6 are original and have not been published yet. EP = Edible portion

Table 4 shows the concentration of ascorbic acid in the main fruits and vegetables consumed in Mexico. Data are presented as mean and standard deviation. It shows that even the concentration of vitamin $C$ is lower in the edible portion in the shells reported in Table 5. 


\begin{tabular}{|c|c|c|}
\hline Food & $\begin{array}{l}\text { Concentration } \\
\text { (mg / } 100 \mathrm{~g} \mathrm{EP} \text { ) }\end{array}$ & $\begin{array}{c}\text { Moisture } \\
\text { (\%) }\end{array}$ \\
\hline squash & $7.2 \pm 0.9$ & 94.2 \\
\hline spinach & $8.5 \pm 0.2$ & 91.6 \\
\hline potatoes & $74.6 \pm 6.7$ & 79.7 \\
\hline cucumber & $93.0 \pm 7.1$ & 96.0 \\
\hline green tomato & $222.8 \pm 10.7$ & 90.9 \\
\hline poblano chile & $191.0 \pm 7.8$ & 91.9 \\
\hline green pepper & $195.5 \pm 9.5$ & 94.3 \\
\hline nopales & $268.9 \pm 30.1$ & 95.2 \\
\hline cambray onion & $17.0 \pm 0.7$ & 93.0 \\
\hline carrot & $50.4 \pm 5.6$ & 87.2 \\
\hline white cabbage & $184.7 \pm 17.2$ & 93.2 \\
\hline grapefruit & $261.3 \pm 10.7$ & 87.8 \\
\hline mango & $319.6 \pm 5.3$ & 84.6 \\
\hline watermelon & $56.2 \pm 8.9$ & 92.5 \\
\hline banana & $333.7 \pm 6.3$ & 76.5 \\
\hline orange & $279.8 \pm 39.4$ & 84.0 \\
\hline mamey & $31.6 \pm 1.2$ & 66.8 \\
\hline plum & $331.1 \pm 17.9$ & 88.1 \\
\hline grape & $66.1 \pm 13.6$ & 84.3 \\
\hline apple & $458.1 \pm 17.8$ & 84.5 \\
\hline beet & $70.8 \pm 6.8$ & 85.3 \\
\hline lemon & $39.4 \pm 2.5$ & 88.3 \\
\hline avocado & $256.2 \pm 61.9$ & 84.3 \\
\hline sweet lime & $306.8 \pm 23.4$ & 89.8 \\
\hline
\end{tabular}

Table 4. Content of ascorbic acid in Mexican fruits and vegetables

The shell or skin of many fruits and vegetables is usually discarded, but these same wastes have significant amounts of ascorbic acid, which is shown in Table 5, where the lime peel, rose apple and apple are the best examples. 


\begin{tabular}{lcc}
\hline Shell of & $\begin{array}{c}\text { concentration } \\
(\mathbf{m g} / \mathbf{1 0 0})\end{array}$ & $\begin{array}{c}\text { moisture } \\
\mathbf{( \% )}\end{array}$ \\
\hline CARROT & $129.1 \pm 10.1$ & 88.5 \\
\hline APPLE & $848.9 \pm 11.2$ & 81.8 \\
\hline BITTER LEMON & $39.4 \pm 2.5$ & 71.7 \\
\hline AVOCADO & $187.1 \pm 27.2$ & 82.0 \\
\hline BEET & $115.8 \pm 1.2$ & 85.8 \\
\hline SMALL POTATO & $4.2 \pm 1.0$ & 85.5 \\
\hline BIG POTATO & $2.1 \pm 0.1$ & 80.3 \\
\hline POMARROSA & $622.9 \pm 35.1$ & 82.5 \\
\hline LIME & $1916.4 \pm 186.7$ & 69.4 \\
\hline CHAYOTE & $19.9 \pm 0.5$ & 94.2 \\
\hline
\end{tabular}

Table 5. Content of ascorbic acid in the shell of some fruits and vegetables

Table 6 shows the values of ascorbic acid in some plant species used as flavoring for Mexican dishes. In most cases the amount used for the preparation of food is very low and sometimes do not amount to more than $2 \%$ by weight of the end plate. However their presence in cooked food gives organoleptic properties suitable for the acceptance of it and especially the potential of the flavors of food.

\begin{tabular}{lcc}
\hline spices & $\begin{array}{c}\text { concentration } \\
\text { (mg /100g EP) }\end{array}$ & $\begin{array}{c}\text { moisture } \\
\text { (\%) }\end{array}$ \\
\hline coriander & $56.0 \pm 7.3$ & 85.3 \\
\hline yerbabuena & $226.9 \pm 21.9$ & 86.8 \\
\hline epazote leaves & $18.3 \pm 1.1$ & 86.3 \\
\hline chard leaves & $8.5 \pm 0.9$ & 92.7 \\
\hline chard stem & $15.7 \pm 0.9$ & 95.0 \\
\hline parsley leaves & $243.9 \pm 17.2$ & 84.5 \\
\hline parsley stem & $182.1 \pm 11.0$ & 90.2 \\
\hline celery leaves & $5.6 \pm 0.2$ & 88.4 \\
\hline celery stem & $7.8 \pm 0.9$ & 90.3 \\
\hline corn grain & $35.3 \pm 6.0$ & 70.7 \\
\hline corn "hair" & $55.9 \pm 1.2$ & 85.4 \\
\hline
\end{tabular}

Table 6. Content of ascorbic acid in some food used as spices 


\section{Food-industrialized}

Vitamin C (ascorbic acid) is water soluble and sensitive to oxygen. For this reason, it may partially destroyed in foods during processing, if exposed to air during storage or if treated with water. Manufacturers can protect them from oxidation by adding vitamin C. The addition of ascorbic acid as an antioxidant should be appropriately marked in the list of ingredients on the label of the final product

Ascorbic acid and its salts are practically insoluble in lipids (fats), for this reason that is often used in the food industry as an antioxidant and preservative greasy foods, in order to avoid rancid. Their salts are usually used with a solubilizing agent (usually a monoglyceride) to improve its implementation. Also this often used in the processing industry of cosmetics products. Sodium ascorbate is a sodium salt of ascorbic acid (vitamin C) and formula $\mathrm{C}_{6} \mathrm{H}_{7} \mathrm{NaO}_{6}$. This form is used in the food industry for their functions antiseptic, antioxidants, and preservatives. Ascorbyl palmitate is an ester formed by ascorbic acid (vitamin C) and palmitic acid creating a liposoluble form of vitamin C. It is used in the food industry as an antioxidant (code E 304). It is wrong to think that is a natural antioxidant

\section{Use as a preservative}

Is usually used as a food preservative and as antioxidant in the food industry, a typical case is found as a bread improver additive. In industry collecting fruit prevents the color oxidative change known browning. Is often added to foods treated with nitrite in order to reduce the generation of nitrosamines (a carcinogen), so commonly found in sausages and cold cuts. In the same way is generally used in the food industry as an acidity regulator.

Ascorbic acid and its sodium, potassium and calcium salts are used widely as antioxidants and additives. These compounds are soluble in water, so that fats do not protect against oxidation. For this purpose may be used ascorbic acid esters with fat soluble long chain fatty acids (palmitate and ascorbyl stearate).

\section{Deficiencies}

\subsection{Primary deficiency - scurvy. Signs and symptoms}

A frank deficiency of vitamin C causes scurvy, a disease characterized by multiple hemorrhages. Scurvy in adults is manifested by lassitude, weakness, irritability, vague muscle pain, joint pain and weight loss. Early signs objectives are as bleeding gums, tooth loss and gingivitis.

The diagnosis of scurvy, is achieved by testing plasma ascorbic acid, low concentration indicates low levels in tissues. It is generally accepted that ascorbic acid concentration in the layer of coagulated lymph (20-53 ug/108 leukocytes) is the most reliable indicator of nutritional status regarding vitamin $\mathrm{C}$ and its concentration in tissues. In the most extreme cases scurvy shows: bleeding gums and skin, perifollicular bleeding and ocular petechiae, salivary and lachrymal glands "drier", functional neuropathy, lower limb edema, psychological disturbances, anemia and poor healing of wounds. The consumption of snuff lowers blood levels of vitamin C. 


\section{Clinical manifestations of Vitamin C deficiency}

Clinical manifestations of deficiency have been described at several levels: a) mesenchymal. By the presence of petechiae, ecchymosis, curly hair, peri-follicular hemorrhages, bleeding gums, swollen, hyperkeratosis, Sjôgren syndrome, dyspnea, arthralgia, edema and poor healing, b) systemics, characterized by fatigue, weakness and lassitude c) psychological and neurological, by the presence of depression, hysteria, hypochondriasis and vasomotor instability.

\subsection{Deficiencies secondary and association with other diseases}

Severe deficiency of vitamin C leads to Scurvy. This rarely occurs but can be observed deficiencies in those who consume a diet without vegetables and fruits, alcoholism, in older people with limited diets, severely ill patients with chronic stress and in infants fed cow's milk.

Symptoms of scurvy are follicular hyperkeratosis, gingival swelling and inflammation (in gums), bleeding gums, loose teeth, dry mouth and eyes, hair loss and dry skin, among other symptoms that can lead to death.

By deficiency of collagen, the wounds do not heal scars and wounds of previous rupture and may lead to secondary infections. Neurotic disorders are common, consisting of hysteria and depression, followed by decreased psychomotor activity. It is not safe indiscriminate administration of ascorbic acid, since as the body becomes saturated, decreased absorption, and giving large doses, abruptly deleted. So if you continue with diet low in vitamin, may appear "rebound scurvy". In addition to "rebound scurvy," gastric intolerance and kidney, its use decreases the cobalamin (vitamin $B_{12}$ ), a substance synthesized by the body.

Eating a balanced and varied diet high in fruits and vegetables, the minimum dose of vitamin C, this completely covered. The daily requirement in an adult male is $90 \mathrm{mg} / \mathrm{d}$ and a woman of $75 \mathrm{mg} / \mathrm{d}$ (mg/day), although there are always situations where it is necessary to increase the dose of vitamin A through supplementation. Such circumstances or situations are: • Pregnancy and Lactation, $\bullet$ Alcoholics and smokers, $\bullet$ diabetics, $\bullet$ Allergic and asthmatic, $\bullet$ People who take daily medications or medications such as oral contraceptives, cortisone, antibiotics, etc.

\section{Anemia by Vitamin C Deficiency}

Anemia of vitamin C Deficiency is a rare type of anemia that is caused by a severe and very prolonged lack of vitamin C. In this type of anemia, the bone marrow produces small red blood cells (microcytosis). This deficiency is diagnosed by measuring the values of vitamin $C$ in white blood cells. One tablet of vitamin C per day corrects the deficiency and anemia cure.

\section{Associated symptoms}

Associated deficiency or lack of vitamin C (ascorbic acid) can produce or be reflected by: Swollen and bleeding gums, dry, rough skin, spontaneous bruising, Impaired wound healing, bleeding nose, joint pain and swelling, anemia and dental enamel weakened. Very small amounts of vitamin $\mathrm{C}$ may be associated with signs and symptoms of deficiency, including: - Anemia, • Bleeding gums, - Decreased, ability to fight infection. - Decrease the rate of 
wound healing. • Dry and separated strands in the hair. $\bullet$ Tendency to bruising. $\bullet$ Gingivitis (gum inflammation). $\bullet$ nosebleeds. $\bullet$ Possible weight gain because of slowed metabolism.

- Rough, dry and scaly. • Pain and swelling of the joints. • Weakened tooth enamel.

\section{Laboratory methods for its measurement in foods and biological fluid}

In the analysis of vitamin $C$, for the methods commonly used consume many time and therefore overestimates the concentration, due to other oxydizable species different of vitamin C; the determination by liquid chromatography of high resolution (HPLC), with electrochemical detection, for example, they require equipment not always available in smalls laboratories and also, is very expensive. However this method quantifies all the forms of the vitamin C present in the sample, and even it detects an epimer of ascorbic acid, the eritorbic acid or isoascorbic acid. The samples of vitamin $C$ saturation are used to establish the deficiency of ascorbate in tissue and are useful to confirm the diagnostic of scurvy when the patient has a normal absorption (Engelfried, 1944). It has been described 3 types of tests to determine the tissue saturation, the first 2 are easy to make but they don't cover the problem on totally, the third test is complicated and it's only useful in research work listed below:

a. Measurement of blood levels with and without a test sample:

- The vitamin C in the plasma is not found doing a metabolic function; it is rather in a transit

- from one tissue to another. Its lost or decrease does not indicates the intracellular status of this vitamin. A well-nourish adult with a free acid ascorbic diet decreases his serum levels of acid to cero in about 6 weeks; however only after many weeks of more deprivation the scurvy symptoms appears. So that for this reason the scurvy patients have low levels of ascorbic acid in the plasma. The vitamin $\mathrm{C}$ determination in plasma after a charge dose generally reflects the vitamin proportion, which has been stored by the tissues, however is tough to do a completely quantitative technique, because in high doses of this vitamin, the plasmatic concentration exceeds the kidney threshold which causes the lost of this vitamin in urine. For a specific measure most be given multiple small doses, to avoid an excess in the blood levels above the renal threshold.

b. Measurement of kidney excretion with and without sample dose: The most important problems in this measurement are those concerning to the collection of urine, more than the vitamin measurement. The excretion of the vitamin has been correlated with the creatinine excretion. This is because the creatinine is used as a real and simple indicator of glomerular filtration.

c. Tissue Measurement This is the one of the 3 techniques which gives a real representation of desaturation of the vitamin. This measurement is difficult because of problems in the sampling of tissue. In the case of ascorbic acid is recommended two methods to measure tissue levels. In the first method is measured its concentration in the buffy coat 
and platelets which correlates good with the first signs of scurvy, making the most recommended technique. The second method determines the tissue saturation grade for an intradermal test, using dichlorophenol indophenol, which depends of skin reductor substances, which made this nonspecific.

\subsection{Spectrophotometric method}

Another proposed method is highly sensitive colorimetric determination of ascorbic acid with 2,4-dinitrophenylhydrazine.

The method can be applied in virtually any laboratory is simple to perform and requires little complicated equipment compared to HPLC. Samples can be from serum to food. In foods the determination may be affected if the food contains natural dyes interfering reading the wavelength of detection. However, it is an easy to implement, since it is inexpensive and sensitive.

The use of UV-Visible spectroscopy (UV-Vis), for the determination of AA, is widely used in research with food, since this acid has strong electronic transitions in the UV region, facilitating their identification and quantification by this technique.

Vitamin $C$ is easily affected by such factors as moisture, light, air, heat, metal ions such as iron and copper, oxygen and the alkaline medium. After decomposition under these conditions is easily transformed into various compounds such as: oxalic acid, L-threonic acid, Lxylonic acid and L-dehydroascorbic acid, and in turn the latter are irreversibly transformed into acid-diketo $2.3 \mathrm{~L}$ gluconic acid, which is its main degradation product.

Within the official methods described for the analysis of vitamin C in tablet, one of the most widely used is the direct titration with 2,6-dichlorophenol indophenol by simple and rapid result. The method is valid if it is known that the composition of the sample no interfering substances and the concentration of dehydroascorbic acid is negligible, therefore, can be applied to a freshly prepared sample, but not useful in stability studies of vitamin C.

\subsection{Chromatographic method (HPLC)}

However, high performance liquid chromatography (HPLC) ensures detection and quantitation limits lower, which also facilitate the elimination of the effects caused by the matrix (interference to other methods of analysis); this technique used as an essential tool in detailed kinetic studies.

Quantification of Ascorbic Acid by HPLC.

Using a standard solution of $50 \mathrm{mg} \mathrm{AA} / \mathrm{L}$ phosphoric acid, $0.05 \mathrm{~N}$ and taking into account the various reports, on the conditions for the quantification of AA in samples, it optimizes the mobile phase and the wavelength of the detector (scanning from 200 to $320 \mathrm{~nm}$ ) to ob- 
tain the greatest sensitivity and resolution in the chromatographic signal. These tests are performed with the following mobile phases:

$2 \% \mathrm{KH}_{2} \mathrm{PO}_{4}, \mathrm{pH}=2.3$

Acetonitrile-Water (70:30)

$1 \% \mathrm{NaH}_{2} \mathrm{PO}_{4}, \mathrm{pH}=2.7$

Methanol-buffer solution: $0.03 \mathrm{M} \mathrm{KH}_{2} \mathrm{PO}_{4}, \mathrm{pH}=2.7$, (99:1)

Water-methanol-acetonitrile (74.4: 25.0: 0.6)

The test is performed with the standard addition curve and calibration curve AA patterns between 1.0 to $25.0 \mathrm{mg} / \mathrm{L}$ phosphoric acid, $0.05 \mathrm{~N}$, to determine the effect matrix in the method of quantification. The proposal is a column Hypersil ODS $C_{18}, 5 \mu \mathrm{m} \times 4.0 \mathrm{~mm} \times 250 \mathrm{~mm}$.

\subsection{Other methods reported}

\section{Iodometric titration}

Ascorbic acid or Vitamin $\mathrm{C}\left(\mathrm{C}_{6} \mathrm{H}_{8} \mathrm{O}_{6}\right)$ can be determined by means of an iodometric titration. Vitamin $\mathrm{C}$ is a mild reducing agent that reacts rapidly with tri-iodide ion, this reaction is generated in a known excess of tri-iodide ion $\left(\mathrm{I}_{3^{-}}\right)$by reacting iodate iodide, is allowed to react and then the excess is titrated by $\mathrm{I}_{3}$-back with a solution of thiosulphate. -The method is based on the following reactions:

$$
\begin{array}{lc}
8 \mathrm{I}^{-}+\mathrm{IO}_{3}-+6 \mathrm{H}^{+} & ------\rightarrow 3 \mathrm{H}_{2} \mathrm{O}+3 \mathrm{I}_{3} \\
\mathrm{C}_{6} \mathrm{H}_{8} \mathrm{O}_{6}{ }^{-}+\mathrm{H}_{2} \mathrm{O}+ & \mathrm{I}_{3}-----\rightarrow \mathrm{C}_{6} \mathrm{H}_{8} \mathrm{O}_{6}+2 \mathrm{H}^{+}+3 \mathrm{I} \\
\text { Ascorbic acid } & \text { dehydroascorbic acid } \\
I^{3-}+2\left(\mathrm{~S}_{2} \mathrm{O}_{3}\right)^{-2} & -----\rightarrow 3 \mathrm{I}^{-}+\left(\mathrm{S}_{4} \mathrm{O}_{6}\right)^{-2} \\
\text { thiosulfate } & \text { tetrathionate }
\end{array}
$$

\section{Requirements and recommendations in Mexico}

The recommended daily ingestion (intake) is of 60 to $100 \mathrm{mg}$ to avoid the appearance of disease symptoms that are produced by deficiencies of this vitamin. The infants require a little more of $100 \mathrm{mg} /$ day, although there is controversy over the minimum amount of this vitamin. We must take into account that this vitamin is very labile at heat and oxygen presence. The ascorbic acid is specific in the treatment of scurvy; the required dose could be better measured by the urinary excretion after a saturation dose. Depending of the required saturation velocity is the daily dose recommended which varies between 0.2 and $2.0 \mathrm{~g} / \mathrm{d}$. In the vitamin $\mathrm{C}$ deficiency, the tissue saturation is obtained with 3 daily 
doses of $700 \mathrm{mg}$ each one for 3 days. Harris and cols. defined the tissue saturation as a sufficient storage of ascorbic acid where occurs a excretion of $50 \mathrm{mg}$ or even more in a period of 4 to 5 hours after 1 dose of $700 \mathrm{mg} / \mathrm{d}$.

The decreased levels in smokers are basically explained because they consume fewer sources of the vitamin. In this kind of population will be required a 50\% more of the recommended dose of the vitamin. Because of the daily recommendation (RDA) it is defined as the daily ingestion average of food which is enough to cover the nutriments required for healthy people in a group of the population, it's necessary to continually assess these recommendations for vitamin $\mathrm{C}$. The totalities of the reviewed information suggest that a consumption of $90-100 \mathrm{mg}$ of this vitamin is enough for the optimum reduction of chronic disease risk in non-smoking men and women. Although some reports are suggested amounts up to $120 \mathrm{mg}$ /day.

\section{Toxicity and hypersensitivity}

High doses of the vitamin (5-15 g/day), may cause osmotic diarrhea because it is ingested more vitamin of which can be absorbed. Also ascorbic acid can provoke intestinal cramps and acidification of the urine, leading to the formation of oxalate stones in the kidney of urinary tract. An exaggerated complementation during pregnancy may high the fetal requirement and result in the presence of scurvy in the newborn. It is also credited with the destruction of vitamin $B_{12}$ of food during the ingestion.

Since the oxalic acid is a metabolite of the catabolism of the ascorbic acid is likely to be the formation of oxalate crystals in kidney in patient's susceptible to nucleation and therefore the formation of crystals or "kidney stones" when it is consumed excess of the vitamin. This relation however does not extend to subjects which are not susceptible to the formation of these kidney stones.

\section{Biochemical functions}

\subsection{Paper as an antioxidant}

Vitamin $C$ is a soluble antioxidant important in biological fluids. An antioxidant is defined as "any substance which, when present in lower concentrations compared with the oxidable substrates (for example, proteins, lipids and carbohydrates and even nucleic acids) avoids or prevent significantly the oxidation of this substratum". The definition also given by the Food Nutrition Board is "A dietary antioxidant is a substance present in food which decreases significantly the adverse effects of the reactive species of oxygen (ROS), reactive species of nitrogen (RNS), or both for the normal physiology function in humans. 


\subsection{Interaction with ROS}

Vitamin C quickly debug the reactive species of oxygen and nitrogen just as superoxide, hidroperoxile radicals, aqueous peroxyl radicals, singlet oxygen, ozone, peroxynitrite, nitrogen dioxide, nitroxide radicals and hypochlorous acid thereby protecting in fact other substrate of the oxidative damage ${ }^{16}$.

Although the AA (ascorbic acid) reacts quickly with the hydroxyl radicals (constant speed > $10^{9} \mathrm{Lmol}^{-1} \mathrm{~s}^{-1}$ ) is clumsy to debug this radical preferentially over other substrates. This is because hydroxyl radicals are very reactive and they will combine immediately with nearest substratum in their environment at a limited speed because of its diffusion. Vitamin $C$ can also act as a co-antioxidant when regenerate the $\alpha$-tocopherol (vitamin E) from the $\alpha$-tocopheroxil radical produced when this is debugged from the lipid-soluble radicals just made. This is a function potentially important because in the in vitro experiments have shown that $\alpha$-tocopherol can act as a pro-oxidant in absentia of co-oxidants just as vitamin C. However the relevance in vivo of the interaction of both vitamins it's not that clear yet.

AA can regenerate urates, glutathione and $\beta$-carotene in vitro from their respective oxidation products with one unpaired electron (urate radicals, glutathionil radicals and cations of $\beta$-carotene radicals). Two important properties of vitamin $C$ make it an ideal antioxidant. The first one is its low potential reduction of ascorbate $(282 \mathrm{mV})$ and its oxidation product with an electron, the ascorbile radical $(2174 \mathrm{mV})$, which is derivates from its functional group en-diol in the molecule. This low potential of reduction of the ascorbate and the ascorbile radical makes them potentially appropriate for oxidation-reduction reactions and that why the vitamin acts as a soluble antioxidant terminal molecule. The second property which makes the vitamin an ideal antioxidant is the stability and the low reactivity of the just made ascorbile radical when the ascorbate debug the reactive species of oxygen and nitrogen. (equation 1).

The ascorbyl radical disproportionate rapidly to form ascorbate and dehydroascorbic acid (equations 1 and 2), or it is retro-reduced to ascorbate by an enzyme semi-dehydroascorbate reductase dependent of NADH. The oxidation product of two AA electrons, dehydroascorbic acid, can be reduced by itself to ascorbate because of the glutathione, by enzymes dependents of glutathione: glutaredoxin (dehydroascorbate oxidoreductase [glutathione dehydrogenase (ascorbate)]) or by an enzyme dependent of selenium (seleno-enzyme): the tioredoxine reductase. Alternatively, the dehydroascorbic acid gets quickly and irreversibly hydrolyzed to 2,3-dicetogulonic acid (ADCG) (equation 3):

$$
\begin{gathered}
\mathrm{AH}_{2} \leftrightarrow \mathrm{A}_{2} \leftrightarrow \mathrm{A} \\
\mathrm{A}_{2}+\mathrm{A}_{2} \rightarrow \mathrm{AH}_{2}+\mathrm{A} \\
\mathrm{A} \rightarrow \mathrm{ADCG} \rightarrow \text { oxalate, threonate, etc. }
\end{gathered}
$$

Where in equation 1 shows the reversible oxidation of 2 ascorbate electrons $\left(\mathrm{AH}_{2}\right)$ to the ascorbile radical $\left(\mathrm{A} \bullet \bullet_{2}\right)$ and dehydroascorbic acid (A) respectively; the equation 2 shows the 
dismutation of the ascorbile radical to transform ascorbate and dehydroascorbic acid; and equation 3 show the hydrolysis of the dehydroascorbic acid to ADCG, which decomposes to oxalate, treonate y many other products. Vitamin $C$ has been recognized and accepted by the FDA as one of 4 dietary antioxidants, the other 3 are vitamin E, $\beta$-carotene precursor of vitamin A and selenium as an essential component of antioxidant enzymes glutathione peroxidase (GPx) and thioredoxin reductase.

Although there is substantial scientific evidence of the role of antioxidant vitamin $C$ and its effects on human health are needed more research that guarantee the role of vitamin both in vivo and in vitro, particularly because the AA is a redox active compound, which may act not only as an antioxidant but also as pro-oxidant in the presence of ion redox active transition metal.

The reduction of metallic ions like iron and copper for the vitamin $\mathrm{C}$ in vitro (equation 4) results in the formation of hydroxyl radicals highly reactive way to the reaction of this ions with hydrogen peroxide, a process known as the Fenton chemistry (equation 5), The lipid hydroperoxides can also "break" because of reduced metallic ions, forming lipid alkoxy radicals (equation 6) which can begin and spread chain reactions of the lipidic peroxidation. However the shown mechanism in the equation 5 requires the availability of free ions, redox active metallic ions and a low index vitamin $\mathrm{C} /$ metallic ion, conditions unlikely under normal conditions in vivo. Although has been shown that in biological fluids like plasma, the vitamin $C$ acts like an antioxidant towards the lipids even in presence of free active ions.

$$
\begin{gathered}
\mathrm{AH}_{2}+\mathbf{M}(n+\mathbf{1}) \rightarrow \mathbf{A}_{2}+\mathbf{M} n+\mathbf{H}+ \\
\mathbf{H}_{2} \mathrm{O}_{2}+\mathbf{M} n \rightarrow \bullet \mathrm{OH}+\mathrm{OH}_{2}+\mathbf{M}(n+\mathbf{1}) \\
\mathbf{L O O H}+\mathbf{M} n \rightarrow \mathbf{L O} \bullet+\mathrm{OH}_{2}+\mathbf{M}(n+\mathbf{1})
\end{gathered}
$$

Where in equation 4 shows the reduction of metallic active redox ions $\mathrm{M}(n+1)$ ] because of the ascorbate to form de ascorbile radical and the reduced metal $(\mathrm{M} n)$, the equation 5 shows the productions of hydroxyl radicals highly reactive $(\bullet \mathrm{OH})$ of the reaction of the hydrogen peroxide $\left(\mathrm{H}_{2} \mathrm{O}_{2}\right)$ with the reduced metallic ions and the equation 6 shows the reaction of the lipid hydroperoxides $(\mathrm{LOOH})$ with the reduced metallic ions to form alkoxy radicals $(\mathrm{LO} \bullet$ ). Although there no convincing evidence of a prooxidant effect of vitamin $C$ on humans, exist a substantial evidence of its antioxidant activity. Interestingly its antioxidant activity does not correlate directly in its anti-curvy effect.

Because of this, the experts considerate that if the antioxidant activity of Vitamin $\mathrm{C}$ is accepted in vivo and that if this is relevant for human health, then scurvy should not be considerate as the only criterion for the nutritional fitness or for determine the ideal quantity or required of the vitamin. 


\subsection{Molecular mechanisms intracellular}

\subsubsection{As an enzyme cofactor}

The molecular mechanisms of the anti-scurvy effect of vitamin $C$ are very broad and so low studied. Also Vitamin C is a cofactor of many involved enzymes in the collagen biosynthesis, carnitine and neurotransmitters. The pro-collagen dioxygenase (proline hydroxylase) and the procolagene-lisine-5-dioxigenese are two enzymes involved in the synthesis of the collagen which needs ascorbic acids for maximum activity. The posttranslational hydroxylation of the lysine and proline residues of these enzymes are indispensable for the synthesis and formation of the stable helix which forms the collagen. So that the difference of the vitamin leads to the formation of weak structures causing lost of teeth, pain in joints, disorders of the connective tissue, and poor healing, characteristic signs of scurvy.

Two dioxigenases involved in the carnitine synthesis also require vitamin $C$ for its activity. Carnitine is essential for the transport of long chain fatty acids to the mitochondria so one deficiency of vitamin $C$ will bring consequences just as fatigue and lethargy which are late symptoms of scurvy. Besides that the vitamin $C$ is a cofactor for the synthesis of catecholamines, in particular for the conversion of dopamine to norepinephrine catalyzed by the enzyme dopamine- $\beta$-monooxygenase. Depression, hypochondriasis, and behavioral changes are common in scurvy as a result of deficient dopamine hydroxylation.

Other kind of enzymes where vitamin $\mathrm{C}$ acts as a cofactor are the ones involved in the peptides amidations and in the tyrosine metabolism (this are also of the mono and dioxygenases kind). It is also implicated in the cholesterol metabolism to bile acids, way of 7- $\alpha$-monooxygenase and in the adrenal steroids metabolism. The hydroxylation of aromatic drugs and carcinogens by cythocrome P-450, gets better also by reducing agents like vitamin C.

The role of vitamin $C$, due to its redox potential is to reduce metal ions present in the active sites of enzymes mono and dioxygenases. Ascorbate for instance acts as a co substrate in these reactions, not as a coenzyme. The reduction of iron, involved by the presence of vitamin improves the intestinal absorption of dietary non heme iron. Other proposals include the maintenance of the thiol groups of proteins, keeping in its reduced form of glutathione addition, a cellular antioxidant and enzyme cofactor, and tetrahydrofolate as a cofactor required for the synthesis of catecholamine.

\section{Ascorbic acid in cancer}

The recommended daily allowance (RDA) for ascorbic acid varies from 100 to $120 \mathrm{mg} /$ day for adults. Have been attributed many benefits just like its antioxidant power, antiatherogenic, anticarcinogenic, immunomodulatory and anti-cold. However these benefits have been subject of debate and controversies because of the danger in the use of mega doses often used and its prooxidant effects and antioxidants. Discussed even if ascorbic acid cause cancer or promote or interfere with cancer therapy, the experts panels of dietary antioxi- 
dants and related compounds have been concluded that the data in vivo does not shows clearly a direct relation between the excess ingestion and the formation of kidney stones, the prooxidant effects and the excess absorption of iron.

The epidemiological and clinic study does not shows conclusive benefic effects in many kinds of cancer, with the exception of stomach cancer. Recently it has tested several derivatives of ascorbic acid on cancer cells as ascorbic acid spheres. The ascorbyl stearate is a compound which inhibits the human carcinogenic cell proliferation, by interfering with the progression of the cellular cycle and inducing apoptosis by modulation of signal transduction pathways. The cancer is a global public health problem with increasing levels of mortality. Although exists a great variety and types of cancer, we can remark the role of vitamin C and its effects in this suffering. AA is effective protecting against the oxidative damage in tissue and also suppressing the carcinogens formation like nitrosamines.

Although vitamin $C$ is a cytotoxic agent for tumor cells and non toxic for normal cells, in modern medicine and conventional favors more the use of powerful toxic chemotherapeutic agents. A great amount of studies have shown that the consumption of vitamin $C$ is inversely related with cancer with protective effects in cancer of lung, pancreas, stomach, cervix, rectum and oral cavity.

The guanine oxidation, a DNA purine, gets reduced significantly after the vitamin C supplementation, but the adenine oxidation, another purine, it's up high which suggest the antioxidant role of the vitamin. Other extensive studies both in vivo and in vitro have shown its ability to prevent, reduce or increase the adverse effects of chemotherapy. The combination of vitamin $\mathrm{C}$ and vitamin $\mathrm{K}$ already given in the chemotherapy increases the survival and the effects of various chemotherapeutic agents in a tumor-ascitic-murine model. The vitamin $\mathrm{C}$ has shown be safe even with the radiotherapy. The co administration of vitamin A, $\beta$-carotene, $\mathrm{E}$ and $\mathrm{C}$ can reduce the incidence and delay the progression of several cancers, such as skin, colon, stomach, esophagus, mammary gland and matrix.

Epidemiologic studies have revealed an inverse relation between the consumption of vi$\operatorname{tamin} \mathrm{A}, \beta$-carotene, $\mathrm{E}$ and $\mathrm{C}$ and the incidence of several human cancers. There are a decrease in the risk and incidence of cancer in populations with high content of vitamins in plasma. The carcinogenesis is related with the cell differentiation, progression, metabolism and synthesis of collagen. The basic mechanism for the carcinogenesis is the cell differentiation because the cancer develops when a lost in this differentiation exists. And here is where the mentioned vitamins have a wide influence over de cell growth and its differentiation. Vitamin $C$ is a strong antioxidant that acts synergistically with vitamin $\mathrm{E}$ in the purification of free radicals which are carcinogenic. The AA as sodium ascorbate exerts marked cytotoxic effects over many human cell lines when they are cultured. These effects are dose dependent.

Lupulescu reported that vitamin C (up to $200 \mathrm{ug} / \mathrm{mL}$ ) did not cause any morphological change in mouse melanoma, neuroblastoma, and mouse and rat gliomas but is lethal for neuroblastoma cells. Cytotoxic effects are dependent cell also because they are stronger in human melanoma cells compared to mouse melanoma. It has even been suggested 
that the cytotoxicity induced by vitamin $C$ is mediated primarily by the formation of hydrogen peroxide in the cell surface. The cytotoxic activity may also be mediated by the presence of cupric ions $\left(\mathrm{Cu}^{2+}\right)$ in malignant melanoma cells that react with vitamin $\mathrm{C}$ to form free radicals in solution. Vitamin $\mathrm{C}$ also invests into cells, transforming them chemically to a normal phenotype fine.

Studies of cell surface and ultrastructure suggest that cancer cells after administration of vitamin $\mathrm{C}$ had cytolysis, cell membrane damage, mitochondrial changes, nuclear and nucleolar reduction and an increase in the formation of phagolysosomes. Changes in cell surface as cytolysis showed predominantly increased synthesis of collagen and disruption of the cell membrane with increased phagocytic activity and apoptotic.

The quantitative estimation of cellular organelles shown that vitamin $C$ affects the intracellular distribution of the organelles, event that plays an important role in the citodifferentiation of the carcinogenic cell and this is the shared effect that not only vitamin $C$ has, but also vitamin A and E. Changes in the Golgi complex and apoptotic activity and autophagic addition to changes in cell surface and in some cases even the reversal of transformed cells to their normal cell types are needed in the possible reduction in incidence of various cancers.

Have also been associated changes in the protein synthesis, DNA and ARA with the differentiation and proliferation cell. But these mechanisms are not clear yet. It have been mentioned that many of this metabolic effects are mediated by the transcription and translation at genomic level. This vitamins modulate the DNA synthesis and the genetic expression in a similarly to hormones and steroids.Their effects can affect the chemical mutagenicity and the cell status. The vitamins can control the cell replication affecting the DNA, RNA and proteins in specific places which are target of electrophyles, promoting the rearrangement of codons in the altered cells and the translocation of specific genes or carcinogens. In this way, vitamins $\mathrm{A}, \mathrm{E}$ and $\mathrm{C}$ affects directly the DNA, RNA and the protein synthesis in the carcinogen cells.

The vitamin C administration decrease the DNA synthesis in the core, the RNA synthesis in the nucleolus and the protein in the cytoplasm of these cells. This inhibition is accompanied by ultrastructural changes mentioned which decreases the cancer progression.

\section{Mechanism of action:}

Have been proposed many mechanisms of the vitamin $C$ activity in the prevention and treatment of cancer:

1. Would improve the immune system by increasing the lymphocytes production.

2. Stimulation in the collagen synthesis.

3. Inhibition of the hyaluronidase, keeping the substances around the tumor intact avoiding metastasis.

4. Inhibition of carcinogen virus

5. Correction of a likely ascorbate deficiency, seen in patients with cancer 
6. Adequate healing after the surgery.

7. Improvement in the effect of some chemotherapeutic agents, just like tamoxifen, cisplatina, DTIC and others.

8. Reduction of the toxicity of other chemotherapeutic agents like adriamicine.

9. Prevention of the cell damage by free radicals.

10. Neutralization of carcinogenic substances.

Patients with cancer tend to immune-undertake, showing low levels of ascorbate in their lymphocytes. The survival of immune system is important both for inhibit the carcinogen cell growth phase and to prevent its proliferation. The supplementation with ascorbate increases the number and the effectiveness of the lymphocytes and upgrades the phagocythosis

The characteristics of the neoplastic cell and its behavior (invasiveness, selective nutrition and possibly accelerated growth) are caused by microenvironmental depolymerization. This destabilization of the matrix is favored by constant exposure to lysosomal glycosidases continually released by the neoplastic cell. The AA is then involved in the control and restriction of this degradative enzyme activity.

The synthesis of collagen is a major factor for the encapsulation of tumors or metastases decreased via the development of a nearly impermeable barrier. AA is necessary for synthesis of collagen and its stabilization. A loss of ascorbate significantly reduces the hydroxylation of proline and hydroxyproline and hydroxylysine to lysine respectively, affecting the cross linking of collagen. This disrupts the structure of collagen triple helix, which increases its catabolism s. In vitro, vitamin C also increases the synthesis of collagen in fibroblasts.

\section{Ascorbic acid in diabetes mellitus}

It has been demonstrated in vitro competition between glucose and ascorbic acid by the cell membrane transporter, granulocytes and fibroblasts, and under conditions of substantial and significant changes in chemotaxis of PMN leukocytes and mononuclear cells. There are significant changes to various chemoattractants, and a significant correlation with the decrease in AA.

These results are consistent with the hypothesis that the chronic hyperglycemia associated with leukocyte AA deficiency, an acute inflammatory response damaged and altered susceptibility to infections, and failure to repair bleeding in these patients, further changes are observed sustained hyperglycemia.

The concentrations of ascorbic acid (AA) are decreased in tissues and plasma in diabetes. These values can be normalized with extra supplements of $20-40 \mathrm{mg} / \mathrm{d}$ or corresponding to its maximum synthetic rate. Treating diabetic rats with this scheme prevents the decreased activity of granulation tissue of proline hydroxylase (Prolasa) an AA-dependent enzyme, re- 
quired to maintain the normal properties of collagen. The decrease in AA concentration in plasma and Prolasa activity in diabetes can be normalized by the inhibitor of aldose reductase. We conclude that in diabetic animals there is a deficiency of AA, which may be responsible for the observed changes in collagen in diabetes.

The decrease in plasma ascorbic acid in diabetes plays an important role in the abnormalities of collagen and proteoglycans. These are the 2 major constituents of the extracellular matrix and its abnormalities are associated with the pathogenesis and complications of diabetes. The structural similarity between glucose metabolism and AA and can interact at the level of the membrane and transporters.

Ascorbic acid enhances the collagen and proteoglycans in fibroblast culture media. This stimulatory action is inhibited by high concentrations of glucose $(25 \mathrm{mM})$. This effect however, is not mediated AA consumption of fibroblasts. Insulin removes the inhibitory effect of glucose on the production of collagen, but the mechanism is not yet known. Thus high concentrations of glucose in diabetes damage the action of ascorbic acid at the cellular level.

\section{Ascorbic acid in essential hypertension (HAS)}

High blood pressure is a powerful indicator of heart disease and stroke. And in many cases is "asymptomatic" or people who have it doing not give importance. However there have been great efforts to use its measurement in the detection of primary or secondary essential hypertension for decades.

Virtually the observed declines in blood pressure and its control in recent years due to better control among individuals diagnosed as hypertensive. In this regard dietary factor has been the best for control. Obesity, dietary sodium and alcohol consumption are strongly associated with low or high blood pressure values.

A high intake of polyunsaturated fatty acids and magnesium are associated with for instance with low pressure. It has also shown an inverse association between plasma vitamin $C$ and blood pressure. Subjects with serum levels of vitamin $C$ equal to $0.5 \mathrm{mg} / \mathrm{dL}$ have a systolic pressure $122 \mathrm{~mm} \mathrm{Hg}$ average compared to subjects with average pressure is $113 \mathrm{~mm} \mathrm{Hg}$ and whose values of serum vitamin $\mathrm{C}$ are $0.9 \mathrm{mg} / \mathrm{dL}$, showing a relative difference of $7 \%$.

These subjects have a similar difference in diastolic pressure ranging from 78 to $73 \mathrm{~mm} \mathrm{Hg}$, a difference of $6 \%$. The prevalence of hypertension was $7.5 \%$ in the group of subjects with low serum vitamin $C$ and only $1 \%$ in subjects with high values of the vitamin in the serum. These results were consistent in several studies regardless of quintiles being compared.

Such relationships have also been identified in Chinese-American population; both men and women aged 60-96 years without antihypertensive treatment. This study revealed a statistically significant difference between the values of systolic and diastolic pressure in upper and lower quintiles of $14 \%(21 \mathrm{~mm} \mathrm{Hg})$ and $9 \%(8 \mathrm{mmHg})$ respectively. It appears that vita- 
min $C$ has a lowering effect on systolic rather than diastolic pressure. Supplementation with vitamin C (1g/day) does not influence the diastolic pressure. Subjects with low vitamin C levels in serum have a high risk of developing stroke compared with those with high values in plasma of the vitamin. Hypertensive subjects, usually overweight, and low levels of serum vitamin $C$ have the same risk.

The increase in the consumption of vitamin $C$ during periods of fat restriction occurs on the one hand a reduction in blood pressure. Low levels of AA in plasma are also associated with low concentrations of 6-keto-prostaglandin F, a prostacyclin. Thus dietary antioxidants enhance the production of prostacyclin for the purification of free radicals and peroxides that inhibit prostacyclin synthase. Vitamin $\mathrm{C}$ and blood pressure then are related, because it has a lowering effect on blood pressure especially when fat intake is low.

\section{Ascorbic acid and cardiovascular disease}

Vitamin $\mathrm{C}$ acts as a regulator of the catabolism of cholesterol into bile acids in the guinea pig and is an important factor in the regulation of lipid in several animal species (rabbit, horse, and rat).

Correlation studies in humans have shown an inverse relationship between vitamin $\mathrm{C}$ intake and mortality from cardiovascular disease.

Experimental and observational studies in humans have been inconsistent but indicate that individuals with high cholesterol consumption, greater than or equal to $5.20 \mathrm{mM} / \mathrm{L}$ $(200 \mathrm{mg} / \mathrm{dL})$ and lower in tissue saturation, increase concentration of vitamin C, which may have a beneficial effect on total cholesterol. This effect is explained by the promotion or inhibition of degradation of prostacyclin and its implications for thrombosis and atherogenesis, in addition to its protective effect on lipid peroxidation. In patients with high cardiovascular risk, supplementation with antioxidant vitamins shows no reduction in overall mortality or incidence of any vascular disease, cancer or other adverse events.

Recent findings indicate a relationship between the nutritional status of vitamin $C$ (as measured by the concentration of ascorbate in serum), biological markers of infection and haemostatic factors and support the hypothesis that vitamin $C$ may protect against cardiovascular events through effects on the haemostatic factors in response to infection.

This relationship is surprising given the uncertainty and potential error in the estimation of consumption of vitamin and vitamin $\mathrm{C}$ status assessment (determined mostly by food intake records of $24 \mathrm{~h}$ blood samples isolated). Add to this the wide variation between subjects is greater than within the same subject.

Lower socioeconomic status and smoking are associated with low concentrations of ascorbate and high concentrations of homeostatic factors that may be confounding factors in cross-sectional studies.

As expected smokers have lower concentrations of AA in serum than non-smokers. The relationship between concentrations of ascorbate and homeostatic factors is very consistent, 
but when cigarette smokers were excluded from the analysis, we obtain an association where smoking becomes a confounding variable. The relationship between fibrinogen, Factor VIIc and ascorbate concentrations were consistent in subjects taking supplements of vitamin $C$ during 1 year, which indicates that the homeostatic factors relate the variability in the status of vitamin $C$ within a range usual dietary.

The inverse association between homeostatic factors and serum concentrations of ascorbate is strong and consistent, however only some markers of infection (e.g. C-reactive protein and $\alpha 1$-antichymotrypsin) are related inversely and significantly with serum ascorbate. It is possible that this low concentration of ascorbate may be the result rather than the cause, of a biological response to infection. The strong relationship between serum ascorbate and dietary intake suggest however that their serum concentrations reflect the nutritional status of the vitamin.

The various studies reported in the literature indicate that vitamin does not prevent respiratory infection but may modulate the biological response, leading to less severe disease, so it has a protective function in lung function.

\subsection{Effect of antioxidants in cardiovascular disease}

It has been suggested a protective effect of antioxidants such as vitamin $C, A$ ( $\beta$-carotene) and $\mathrm{E}$ plus selenium in cardiovascular disease. Prospective studies so far have documented an inverse relationship between vitamin $C$ intake and cardiovascular disease, and a strong protective effect of vitamin E supplementation on coronary patients.

Finnish and Swiss studies showed that blood levels of ascorbate and therefore a diminished nutritional status of vitamin predicts myocardial infarction. Low levels of vitamin $C$ increased to 2.7 times the risk of myocardial infarction and this is independent of other risk factors. Mediterranean studies showed a $70 \%$ reduction in mortality and risk of myocardial infarction independent of the effect on blood pressure and lipids. Any protective effect on heart disease of these antioxidants is mediated by the oxidation of LDL cholesterol, but there may be other mechanisms of homeostasis and inflammation.

\subsection{Infection, homeostasis, and cardiovascular disease}

Fibrinogen and factor VII are recognized risk factors of myocardial infarction and stroke, in the same way that acute and chronic infection and increased white blood cell count are risk factors for cardiovascular disease. The infection may contribute to the inflammatory process observed in atherosclerosis.

C-reactive protein and alpha- 1 antichymotrypsin are acute phase proteins are synthesized in hepatocytes in large numbers in inflammatory processes. This synthesis is mediated primarily by IL- 6 produced by monocytes and macrophages. Elevated fibrinogen favors these mechanisms and therefore an increased cardiovascular risk. In this way a reduction in dietary intake in winter for instance, would lead to lower serum ascorbate levels, an increase in susceptibility to infection and the factors haemostatic factors and therefore to an increase in cardiovascular mortality. 
According to the seasonal variations of vitamin C intake may be relatively low $(<80 \mathrm{mg} /$ day on average), corresponding to serum ascorbate concentrations of $50 \mathrm{umol} / \mathrm{L}$. within this range may be variations in infection and homeostatic markers. Increased intake of vitamin $\mathrm{C}$ to $90-100 \mathrm{mg} /$ day can increase in these subjects more than $60 \mathrm{umol} / \mathrm{L}$, which has a significant effect on all risk factors.

\section{Ascorbic acid and immunity}

In stress situations the adrenal glands react liberating a large number of active and ready hormones. It has been suggested that $200 \mathrm{mg}$ of vitamin C per day can reduce stress levels caused by these hormones. The stress suppresses the immune response. Megadoses of vitamin C increases the body levels of antibodies in animal models (rats stressed and unstressed) having the highest values stressed rats. Stressed animals may need more vitamin C for proper immune system function.

Healing is characterized by synthesis of connective tissue, whose main component is collagen. This molecule AA required for cross linking of the fibers in hydroxylated residues of prolyne and lysine. Ascorbic acid supplementation is necessary for healing since this is oxidized during the synthesis of collagen.

There is an undeniable evidence of the interaction of vitamin C and phagocytes. The collected cells from the blood, peritoneal or alveolar fluid usually contain high concentrations of vitamin $\mathrm{C}$ (1-2 ug/mg protein). Guinea pig neutrophils produced $\mathrm{H}_{2} \mathrm{O}_{2}$ and destroy staphylococci in the same way they do control cells. Both ascorbate as dehydroascorbic acid are used for phagocytic process. Neutrophils can avoid self-poisoning absorb extra amounts of ascorbic acid, which can neutralize the antioxidants. However glucolytic activity does not increase much in the neutrophils of guinea pigs supplemented and the stimulation of NADPH oxidase activity is depressed. The addition of ascorbate to the culture media of normal macrophages increases the concentration of cyclic GMP (cGMP) in addition to the route of pentose or hexose monophosphate.

Although the addition of large amounts of ascorbate can inhibit myeloperoxidase activity is not altered its bactericidal capacity. It has been an increase in the bactericidal activity in mouse peritoneal macrophages by the addition of ascorbate to the medium. Besides ascorbate increase the motility and chemotactic activity of these cells. The motor functions of cells as the random motion and chemotactic migration of neutrophils and macrophages is damaged in the absence of vitamin C. Ascorbic acid can also influence the ability of certain cell lines to produce interferon. The addition of AA to cultures of skin embryonic or fibroblasts leads to the production of interferon.

Vitamin $C$ is also necessary for thymic function and operation of certain cells involved in the production of thymic humoral factor. Thymic content of dehydroascorbate diminishes in direct proportion to vitamin $\mathrm{C}$ intake. The hormonal activity of thymic extracts correlates with thymic ascorbate and inversely with dehydroascorbate. 


\section{Ascorbic acid and gallbladder}

The gallbladder disease is highly prevalent in the U.S. and in Mexico, remains a serious public health problem. It has been estimated that only about in U.S. 20 million Americans have gallstones partially or entirely composed of cholesterol. Gallstones form when bile supersaturated with cholesterol is destabilized. AA affects a limiting step in the catabolism of cholesterol into bile acids in experimental animals, as described AA-deficient guinea pig common development of cholesterol gallstones.

Because of this it has been hypothesized that the deficiency in humans may be a risk factor for this disease in humans. The main findings in humans have shown an inverse relationship between serum levels of AA and biliary disease prevalence among women. It was also observed a low prevalence of clinical biliary disease between women taking ascorbic acid supplements. However, this prevalence has not been observed in males. Almost all the findings from different countries agree to respect.

In another study, Simon showed that the use of ascorbic acid supplementation correlates with biliary disease among postmenopausal women with coronary disease. Among women who consumed alcohol, the use of ascorbic acid supplementation was associated independently with a $50 \%$ reduction in the prevalence of gallstones and $62 \%$ for cholecystectomies.

Within the NHANES III study was not observed association, linear or nonlinear, between serum ascorbic acid and prevalence of biliary disease in men. Reflecting the low prevalence of the disease in men and reduced statistical power to detect such an association.

It has been hypothesized that the inverse relationship between AA and biliary disease, demonstrated in animals, affects the activity of the enzyme cholesterol-7- $\alpha$-hydroxylase, which is the limiting step that regulates the metabolism of cholesterol into bile acids. Supplementation with ascorbic acid increases the activity of the enzyme up to 15 times compared with the vitamin-deficient animals that develop the formation of cholesterol gallstones. Additionally there is a hypersecretion of mucin, a glycoprotein that is secreted by the epithelium of the gallbladder, which precedes cholesterol destabilization and gallstone formation. Because oxygen and hydroxyl radicals stimulate mucin hypersecretion, inhibition of the oxidative changes in the vesicle due to AA can decrease the production of this glycoprotein.

\section{Ascorbic acid in other conditions}

\subsection{Sjögren's syndrome}

\subsubsection{Vitamin C and Sjögren syndrome}

Primary Sjögren's syndrome (SSP) is a chronic disorder of unknown cause, characterized by dry eyes and mouth. It usually occurs in middle-aged women with a prevalence of 1:5000. Patients may have swelling of joints, muscles, nerves, thyroid, kidneys or other 
body areas. These symptoms result from lymphocytic infiltration and destruction of these tissues.

The diagnosis is based on clinical examination of the eyes and mouth, blood tests specific (auto antibodies) and biopsy of minor salivary gland (taken from inside the inner lip). Sjögren's syndrome is not fatal, but must be addressed quickly to prevent complications due to dry mouth (caries, abscesses, gingivitis) and eyes (corneal erosion, infection). However, there is no therapy available that "removes" these symptoms because all therapies are directed at eliminating the symptoms and prevent complications.

On the other hand there are several studies that reported a direct relationship between the clinical manifestations of Sjögren's syndrome and those caused by deficiency of ascorbic acid (vitamin C): scurvy. A frank deficiency of vitamin C causes scurvy, a disease characterized by multiple hemorrhages. Scurvy in adults is manifested by latitude, weakness, irritability, vague muscle pain, joint pain and weight loss. Early signs are objective as bleeding gums, tooth loss and gingivitis.

The diagnosis of scurvy, is achieved by testing plasma ascorbic acid, low concentration indicates low levels in tissues. It is generally accepted that ascorbic acid concentration in the layer of coagulated lymph (20-53 ug/10 leukocytes) is the most reliable indicator of nutritional status regarding vitamin $\mathrm{C}$ and its concentration in tissues and serum.

\subsection{Pharmacological data}

Ascorbic acid is specific in the treatment of scurvy; the dose required can best be measured by determining urinary excretion after a dose of saturation, depending on the speed at which the saturation is required is the recommended daily dose ranging from 0.2 and $2.0 \mathrm{~g} /$ day. In the vitamin deficiency $C$ tissue saturation is achieved with three daily doses of $700 \mathrm{mg} \mathrm{c} / \mathrm{u}$, for three days. Harris defined as saturation of tissues, a sufficient store where an ascorbic acid excretion $50 \mathrm{mg}$ or more occurs in a period of 4 to 5 hours after a dose of $700 \mathrm{mg} /$ day.

\subsection{Previous experience in animals}

Kessler in his study reported that rats which have been induced vitamin C deficiency, develop various manifestations of primary Sjögren's syndrome (SSP), such as infiltration of mononuclear cells in salivary and lachrymal glands and that these were more severe is female rats than in male rats, concluding that these pathological changes are similar to those that characterize the syndrome in humans.

In previous studies Hood reported a direct relationship between the manifestations of primary Sjögren's syndrome (xerostomia and xerophthalmia) and clinical signs of scurvy such as gingivitis, periodontal bleeding and loss of teeth. In their study, Hood study 5 subjects men whose diets did not contain ascorbic acid, for 84 to 97 days. During the deficiency, in the demonstrations that make Sjögren syndrome, observed that prostaglan- 
dins, particularly $\mathrm{PGE}_{1}$, is important in the immune defects associated with the syndrome.

In 1992, Gomez et al, from the National Institute of Medical Sciences and Nutrition "Salvador Zubiran", observed values less than $0.2 \mathrm{mg}$ AA/dl in plasma of patients with SSP (reference values were from 0.4 to $2.0 \mathrm{mg} / \mathrm{dL}$ ), representing a frank deficiency of vitamin in $100 \%$ of cases with SSP.

\subsection{Role of vitamin $\mathrm{C}$ in other body disorders}

It is reported that the diabetic individual has low levels of vitamin $C$ in plasma and leukocytes, which is our immune defense. However, more clinical studies, in a large scale, are needed to determine whether the supplementation with large doses of the vitamin are beneficial or not. Some studies have shown that supplementation with $2 \mathrm{~g} / \mathrm{d}$, decreased glucose levels in diabetics and reduce capillary fragility.

Megadoses of vitamin $\mathrm{C}$ can still be toxic in diabetics with kidney disorders. It was mentioned that vitamin $C$ also helps to reduce body glycosylation, which shows abnormalities in the binding of sugars and proteins. In addition vitamin $C$ reduces the accumulation of sugar sorbitol which damages eyes and kidneys. Vitamin C lowers blood pressure and plasma cholesterol helping to keep the blood flowing and protected from oxidation in a synergistic action with vitamin E. In doses of $1 \mathrm{~g} /$ day protects the body against LDL lipoproteins.

Atherosclerosis is the best contributor to heart disease. Vitamin $C$ prevents the formation of atheromatous plaque by inhibiting the oxidative modification of LDL's, which contributes to atherosclerotic process for their cytotoxic effects, inhibition of receptor radical scavengers and their influence on the motility of monocytes and macrophages.

Vitamin C also helps to prevent atherosclerosis through the synthesis of collagen in the arterial wall and prevent undesirable adhesion of leukocytes to the damaged artery.

Supplementation with $2 \mathrm{~g} /$ day reduces the adhesion of monocytes to blood vessels, effectively reverses the vasomotor dysfunction observed in patients with atherosclerosis. In addition these doses increase HDL, being highly protective against heart attacks and stroke. Risk is reduced by up to $62 \%$ in subjects consuming $700 \mathrm{mg} /$ day compared with those consuming $60 \mathrm{mg} /$ day or less. Only Joel study has shown that low levels of ascorbic acid in serum (AAs) are marginally associated with an increased risk and fatal cardiovascular disease was significantly associated with an increased risk of mortality for all causes. Low levels of AAs are also a risk factor for cancer death in men, but unexpectedly it was associated with a decreased risk of cancer death in women.

Vitamin C has an effect antihistaminic. Subjects with low plasma vitamin C levels have elevated blood histamine and vitamin supplementation, reduces these levels. Table 7 shows the relationship of vitamin $\mathrm{C}$ reported in different conditions. 


\begin{tabular}{ll}
\hline Low concentrations of AA & High concentration of AA \\
\hline Rheumatoid arthritis (Lunec) & Cancer in women (Joel) \\
Cancer in Men (Joel) & Uric Acid Excretion (Stein) \\
Asthma (Ruskin) & Back pain and spinal discs. \\
Bronchospasm & Antioxidant (Kahn) \\
Cataract (Jackes) & Allergic process (Ruskin) \\
Aging (Jackes) & Blood pressure (Ringsdorff) \\
Retinopathy (Crary) & Constipation (Sindair) \\
(Macular Degeneration) & Probable association with menopause. (Smith) \\
\hline
\end{tabular}

Figures in parentheses indicate the reference.

Table 7. Association of serum vitamin C (ascorbic acid) in serum or plasma in different symptoms and diseases.

\section{Author details}

José Luis Silencio Barrita ${ }^{1}$ and María del Socorro Santiago Sánchez ${ }^{2}$

1 Association of Chemists, National Institute for Medical Sciences and Nutrition "Salvador Zubiran", Mexico

2 Department of Nutrition and Dietetics, General Hospital No, 30 "Iztacalco", Mexico

\section{References}

[1] Akhilender Naidu K Vitamin C in human health and disease is still a mystery? An overview. Nutr J 2003, 2:1475-2891-2-7

[2] Anitra C Carr and Balz Frei.Toward a new recommended dietary allowance for vitamin $C$ based on antioxidant and health effects in humans Am J Clin Nutr 1999;69:1086-107

[3] Ascencio C., Gomez E., Ramirez A., Pasquetti A., Bourges H. Dietary habits and nutrient intake in patients with primary Sjögren's syndrome.7th International Congress of Mucosal Immunology. August 16-20, 1992, Prague, Czechoslovaquia.

[4] Bergman F, Curstedt T, Eriksson H, van der Linden W, Sjo ${ }^{\circ}$ vall J. Gallstoneformation in guinea pigs under different dietary conditions: effect of vitamin $\mathrm{C}$ on bile acid pattern. Med Biol. 1981; 59:92-98.

[5] Blomhoff R. Dietary antioxidants and cardiovascular disease Curr Opin Lipidol 16:47-54. \# 2005

[6] Bowes and Church.- Food values of portions commonly used. Lippincot Co.,1975. 
[7] Bourges H. Madrigal H. Chavéz A., Tablas del valor nutritivo de los alimentosmexicanos. Publicación L-12 INN, 1983, 13 ed. México.

[8] Bradley A.V. Tables of food values, Chas A. Bennet Co. 1976.

[9] Cameron E, Pauling L. Supplemental ascorbate in the supportive treatment of cancer: Prolongation of survival times in terminal human cancer. Proc Natl Acad Sci 1976; 73:3685-3689.

[10] Chen Qi, Espey M G, Krishna MC, Mitchell JB, Corpe CP, Buettner GR, Shacter E, Levine M. Pharmacologic ascorbic acid concentrations selectively kill cancer cells: Action as a pro-drug to deliver hydrogen peroxide to tissues. PNAS 2005, 102(38): 13604-13609

[11] Crary, E.J. and M.F. McCarty, 1984. Potential clinical applications for high-dose nutritional antioxidants. Med. Hypoth., 13: 77-98.

[12] Drake IM, Davies MJ, Mapstone NP, Dixon MF, Schorah CJ, White KLM, Chalmers DM, Axon ATR. Ascorbic acid may protect against human gastric cancer by scavenging mucosal oxygen radicals. Caranogenesis. 1996, 17 (3):.559-562,

[13] Engelfried J.J. The ascorbic acid saturation test. J.Lab. Med. 1944, 29:234

[14] F.J. de Abajo y M. Madurga. Vitamina C: aplicaciones terapéuticas en la actualidad. Med Clin (Barc) 1993; 101: 653-656

[15] Fisher E, McLennan SV, Tada H, Heffernan S, Yue DK, Turtle JR. (Interaction of ascorbic acid and glucose on production of collagen and proteoglycan by fibroblasts. Diabetes, 1991, 40(3):371-6)

[16] Gueguen S, Pirollet P, Leroy P, Guilland JC, Arnaud J, Paille F, Siest G, Visvikis S, Hercberg S, Herbeth B. Changes in Serum Retinol, $\alpha$-Tocopherol, Vitamin C, Carotenoids, Zinc and Selenium after Micronutrient Supplementation during Alcohol Rehabilitation. J Am Coll Nutr, 2003, 22:303-310

[17] Gomez E, Silencio JL, Bourges H. Vitamin B2, B6 and C status in patients with primary sjögren's syndrome. 7th International congress of mucosal immunology, august 16-20, 1992, Prague Csechoslovaquia.

[18] Harris J.L. Vitamin C saturation test. Standarization meassurements at graded levels of intake. Lancet 1943, 1:515,

[19] Head KA, Ascorbic Acid in the Prevention and Treatment of Cancer. Altern Med Rev 1998; 3(3):174-186)

[20] Herrera, V. Más evidencia en contra del uso de vitaminas y antioxidantes en la prevención de enfermedades crónicas Evidencia Actualización en la Práctica Ambulatoria- 2002, 5(6): Nov-Dic

[21] Hoffman-La Roche F. Compendio de vitaminas, 1970, Basilea, Suiza. 
[22] Hood J., Burns Ch.A., Hodges R.E. Sjögren's syndrome in scurvy. N. Engl. J. Med. $1970,282: 1120$

[23] Horrobin D.F., Manku M.S. The regulation of prostaglandin E1 formation: A candidate for one of the fundamental mechanism involved in the actions of vitamin C. Med. Hypotheses. 1979, 5:849.

[24] Ip C. Interaction of vitamin C and selenium supplementation in the modification of mammary carcinogenesis in rats. J Natl Cancer Inst 1986;77:299-303.

[25] Iqbal K, Khan A Ali Khan Khattak MM. Biological Significance of Ascorbic Acid (Vitamin C) in Human Health: A Review Pakistan J Nutr 2004, 3(1):5-13,

[26] Jacob RA, Pianalto FS, Agee RE. Cellular ascorbate depletion in healthy men. J Nutr. 1992; 122:1111-1118.

[27] Jacques, P.F., L.T. Chylack, R.B. McGandy and S.C Hartz, 1988. Antioxidant status in persons with and without senile cataract. Arch Ophthalmol, 106: 337-340.

[28] Jenkins SA. Biliary lipids, bile acids and gallstone formation in hypovitaminotic C guinea-pigs. Br J Nutr. 1978;40:317-322

[29] Jenkins SA. Hypovitaminosis C and cholelithiasis in guinea pigs. Biochem Biophys Res Commun. 1977; 77:1030-1035.

[30] Kahn, H.A., H.M. Leibowitz and J.P.Ganley, 1977. The Framingham Eye Study: Outline and major prevalence findings. Am. J. Epidemiol., 106: 17-32.

[31] Kathleen A. Head, N.D. Ascorbic Acid in the Prevention and Treatment of Cancer Altern Med Rev 1998; 3(3):174-186

[32] Kessler S. A laboratory model for Sjögren syndrome. Lancet 1968, 52:671

[33] Khaw KT, Woodhouse P. Interrelation of vitamin C, infection, haemostatic factors, and cardiovascular disease BMJ 1995; 310:1559-1563

[34] Lunec, J.B., 1985. The determination of dehydroascorbic acid and ascorbic acid in the serum and sinovial fluid of patients with rheumatoid arthritis. Free Radical Research Communications, 1: 31-39.

[35] Lupulescu A The Role of Vitamins A, B Carotene, E and C in Cancer Cell Biology. Intern. Vit. Nutr. Res. 1993; 63:3-14.

[36] Marks J. A guide to the vitamins, their role in health and disease. MTP Medical and Technical Pub. 1975, England.

[37] McLennan S, Yue DK, Fisher E, Capogreco C, Heffernan S, Ross GR, Turtle JR. Deficiency of ascorbic acid in experimental diabetes. Relationship with collagen and polyol pathway abnormalities. Diabetes, 1988 ,37(3):359-361, 
[38] MRC/BHF Heart Protection Study of antioxidant vitamin supplementation in 20.536 high-risk individuals: a randomised-placebo controlled trial. Heart Protection Study Collaborative Group. The Lancet 2002;360:23-33

[39] Mullan BA, Young IS, Fee Hd, McCance DR. Ascorbic Acid Reduces Blood Pressure and Arterial Stiffness in Type 2 Diabetes Hypertension. 2002; 40:804-809

[40] Omaye, T.,Scala J.H., Jacob R.A. Plasma ascorbic acid in adult males: effect of depletion and supplementation. Am. J. Clin. Nutr. 1986, 44: 257,

[41] Paul A.A., Southgate D.A. The composition of foods, 14th edition Elsevier/North Holland Biomedical Press, 1985.

[42] Pecoraro RE, Chen MS. Ascorbic acid metabolism in diabetes mellitus. Ann New York Acad Sci, 1987, 498(1): 248-258,

[43] Ringsdorf, W.M. Jr. and E. Cheraskin, 1981. Ascorbic acid and glaucoma: A Rev. J. Holistic. Med., 3: 167-172.

[44] Roe J.H., Kuether C.A. determination of ascorbic acid in wholeblood and urine through the 2,4-dinitotrophenylhydrazine derivative of dehydroascorbic acid. J. Biol. Chem, 1942, 147:399 .

[45] Rogur L, Lundblad and Fiona M . MacDonald. Handbook of Biochemistry and Molecular Biology, Fourth Edition, Edited by CRC Press 2010 Pages 243-250

[46] Rose C. R., Nohrwld L.D. Quantitative analysis of ascorbic acid and dehydroascorbic acid by High Performance Liquid Chromatography Anal. Biochem. 114:140, 1981.

[47] Rune Blomhoff. Dietary antioxidants and cardiovascular disease. Curr Opin Lipidol 16:47-54. \# 2005

[48] Ruskin, S.L., 1947. Sodium ascorbate in the treatment of allergic disturbances. The role of adrenal cortical hormone-sodium-vitamin C. Am. J. Dig. Dis.,14: 302-306

[49] Sahyoun, R.N.,1996. Carotenoids, vitamins C and E and mortality in an elderly population. Am. J. epidemio.,144: 501-511.

[50] Sánchez-Moreno C, Cano MP, de Ancos B, Plaza L, Olmedilla B, Granado F, Martín A.Effect of orange juice intake on vitamin $\mathrm{C}$ concentrationsand biomarkers of antioxidant status in humansAm J Clin Nutr 2003; 78:454-60.

[51] Silencio Barrita JL Vitaminas: conceptos generales, Nutr clin 2006;9(3):36-44

[52] Simon JA., Esther SH, Jeffrey AT. Relation of serum ascorbic acid to mortality among US adults. J. Am. College of Nutr, 2001.20(3);456

[53] Simon JA, Hudes ES. Serum Ascorbic Acid and Gallbladder Disease Prevalence Among US Adults. The Third National Health and Nutrition Examination Survey (NHANES III) Arch Intern Med. 2000; 160:931-936

[54] Simon JA. Ascorbic acid and cholesterol gallstones. Med Hypotheses. 1993; 40:81-84. 
[55] Simon J.A Vitamin C and cardiovascular disease: a review J Ame Collage of Nutr, 1992, 11 (2):107-125

[56] Simon JA, Hudes ES, Tice JA. Relation of serum ascorbic acid to mortality among US adults. J Am Coll Nutr 2001; 20:255-63.

[57] Simopoulos AP. Human requirement for N-3 polyunsaturated fatty acids. Poult Sci. 2000 Jul;79(7):961-70.

[58] Spittle C.R. Artherosclerosis and vitamin C. Lancet, december 11:1280, 1971.

[59] Stein, H.B., 1976. Ascorbic acid-induced uricosuria: a consequence of megavitamin therapy. Ann. Intern.Med., 84: 385-388.

[60] Sinclair AJ, Girling AJ, Gray L. an investigation of the relationshipbetween free radical activity and vitamin C metabolism in ederly diabetic subjects with retinopathy. Gerontology 1992, 38:266-274

[61] Smith CJ. Non-hormonal control of vaso-motor flushing in menopausal patients . Chicago med, 1984.

[62] Valk EE, Hornstra G Relationship between vitamin E requirement and polyunsaturated fatty acid intake in man: a review. Int J Vitam Nutr Res. 2000 Mar;70(2):31-42.

[63] Walingo KM. Role of vitamin C (ascorbic acid) on human health- A review. African J Food Agric Nutr Dev (AJFAND): 2005, 5(1):1-25

[64] Watt B.K. A.L. Composition of foods. Agriculture Handbook num. 9, United States, Departament of Agriculture, USA, 1975.

[65] Yi Li and Herb E. Schellhorn*New Developments and Novel Therapeutic Perspectives for Vitamin C J. Nutr. 2007, 137: 2171-2184, 